\title{
HER2-positivity in mucinous cancer might be related to accompanying infiltrating ductal carcinoma histology
}

\author{
Kadri Altundag ${ }^{1}$
}

Received: 29 February 2020 / Accepted: 6 March 2020 / Published online: 11 March 2020

○) Springer Science+Business Media, LLC, part of Springer Nature 2020

\section{To the editor,}

I wish to congratulate Kim and his colleagues for their article [1] in which they investigated the prognostic value of human epidermal growth factor receptor 2 (HER2) status and the efficacy of anti-HER2 therapy in patients with hormone receptor (HR)-positive mucinous carcinoma (MC) of the breast. A total of 2716 HR-positive MC patients were enrolled and followed up for a median 100.1 months. Of these, 2094 (77.1\%) were HER2-negative and 228 (8.4\%) were HER2-positive. They reported that HER2-positive status was associated with worse prognosis in HR-positive and node-positive MC. As authors mentioned that the type of MC (pure vs mixed) was not recorded. In our database, including 6528 invasive breast cancer patients, all HER2positive MC cases were mixed MC with infiltrating ductal carcinoma (IDC) and mucinous pathology. This finding suggests correlation between HER2 overexpression in MC and IDC of the breast and sheds more light on further characterization of patients with HER2-positive MC of the breast.
Funding No funding.

\section{Compliance with ethical standards}

Conflict of interest I declare that I have no conflict of interest.

Ethical approval This article does not contain any studies with human participants or animals performed by any of the authors.

Informed consent Not applicable.

\section{Reference}

1. Kim HS, Yoo TK, Park WC, Chae BJ (2020) The prognostic value of HER2 status and efficacy of anti-HER2 therapy in patients with HR-positive mucinous breast cancer: a nationwide study from the Korean Breast Cancer Society. Breast Cancer Res Treat. https:// doi.org/10.1007/s10549-020-05550-4 [Epub ahead of print]

Publisher's Note Springer Nature remains neutral with regard to jurisdictional claims in published maps and institutional affiliations.

This letter to the editor refers to the article available at https://doi. org/10.1007/s10549-020-05550-4.

Kadri Altundag

altundag66@yahoo.com

1 MKA Breast Cancer Clinic, Tepe Prime, Cankaya, 06800 Ankara, Turkey 